ISBN 978-93-84422-79-0

2017 International Conference on Building Design, Civil, Architectural and Transportation Engineering

(BDCATE-2017)

Singapore Aug. 10-11, 2017

\title{
Shear Behavior and Capacity of CIP Anchors Installed in Steel Fiber-Reinforced Concrete
}

\author{
Jong-Han Lee ${ }^{1}$, Kun-Joon Lee ${ }^{1}$ and Backsoon Cho ${ }^{2}$ \\ ${ }^{1}$ Department of Civil Engineering, Daegu University, Gyeongsan 38453, Republic of Korea \\ ${ }^{2}$ Department of Civil Engineering, Inje University, Gimhae 50834, Republic of Korea
}

\begin{abstract}
This study investigated the shear breakout failure of cast-in-place anchors in steel fiber-reinforced concrete. The experimental results showed that the cracking strength of the anchors is similar regardless of the steel fiber content. After the concrete cracking, the load and displacement resistance increased in the anchors in the SFRC with increasing fiber volume fraction of steel fibers. The ultimate strength of the SFRC anchors almost linearly increased up to the steel fiber volume fraction of $1.0 \%$.
\end{abstract}

Keywords: CIP anchor, steel fiber, fiber-reinforced concrete, concrete breakout capacity

\section{Introduction}

Concrete anchors have been used as important elements to connect structural and non-structural elements to concrete. Anchors installed in concrete fail due to steel fracture of the anchor or concrete fracture under tensile or shear loadings [1]. Fig. 1 shows the concrete breakout failure mode of anchors. Concrete breakout failure is induced by a high stress concentration at the anchor, which initiates and rapidly propagates cracks through concrete with low toughness and ductility [2]. Steel fiber-reinforced concrete (SFRC) is a composite material that improves the brittle characteristic of conventional concrete. The inclusion of a sufficient amount of steel fibers in concrete improve the shrinkage resistance of concrete [3] as well as significantly increases the tensile strength and ductility of members [4,5]. Kwak et al. [6] emphasized that the shear resistance was greatly improved at the cracking interface of SFRC members. In addition, the current main design standards, ACI 31811 [2] and ETAG 001 [7], evaluate the breakout failure of anchors only in the plain concrete (or, unreinforced concrete) using the concrete capacity design (CCD) method, which idealizes the failure mode in a half-pyramid shape under shear loading. Therefore, an experimental study was performed assess the shear behaviour and capacity of cast-in-place (CIP) anchors in concrete reinforced with steel fibers.
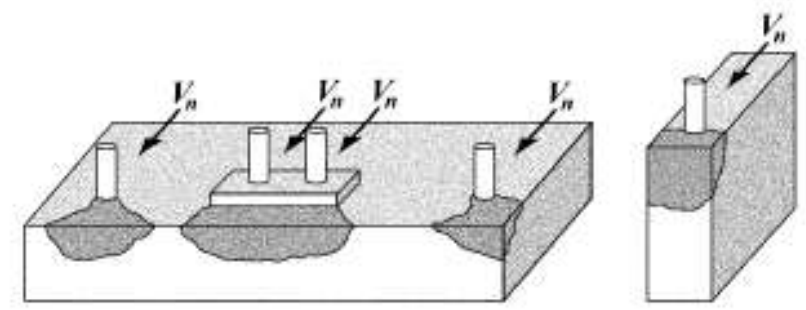

Fig. 1: Concrete breakout failure mode, taken from ACI 318-11 [2] 


\section{Experimental Program}

This study designed the anchor specimens in SFRC with the fiber volume fraction of $0.33 \%, 0.67 \%$, and 1.00\%. Fig. 2 depicts the installation and instrumentation of the specimen. The amplitude of the applied load was measured using an actuator with a capacity of $200 \mathrm{kN}$ and displacement using a linear variable differential transformer (LVDT). The steel anchor used in the study is $30 \mathrm{~mm}$ in diameter with an edge distance of $150 \mathrm{~mm}$ and an effective length of $240 \mathrm{~mm}$.

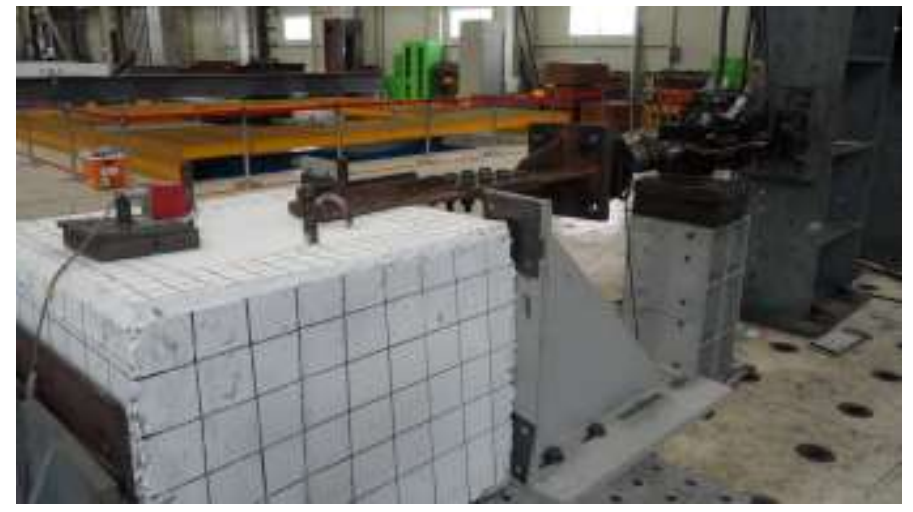

Fig. 2: Test setup and instrumentation

\section{Experimental Results}

\subsection{Failure Shape}

Figs. 3 and 4 show the failure shapes of the anchors in the unreinforced and SFRC concrete, respectively. The anchor in the unreinforced concrete suddenly failed in a shape of a wedge block as the first crack occurred and rapidly propagated. On the other hands, in the SFRC, after the first concrete cracking, additional cracks occurred and slowly propagate to fail the anchor.

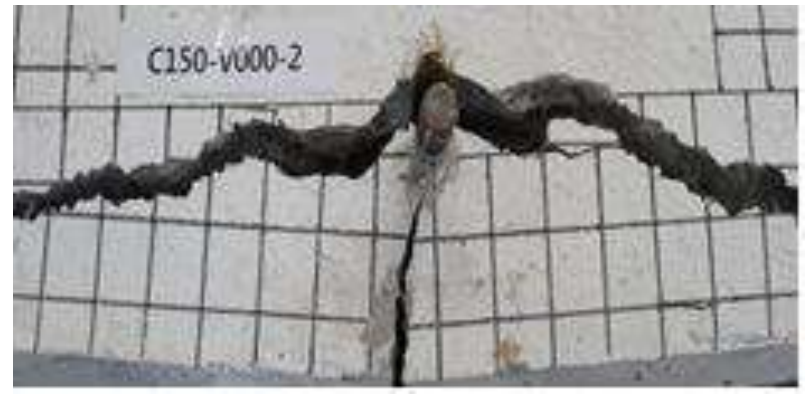

Fig. 3: Failure shape of the anchor specimen in the plain concrete

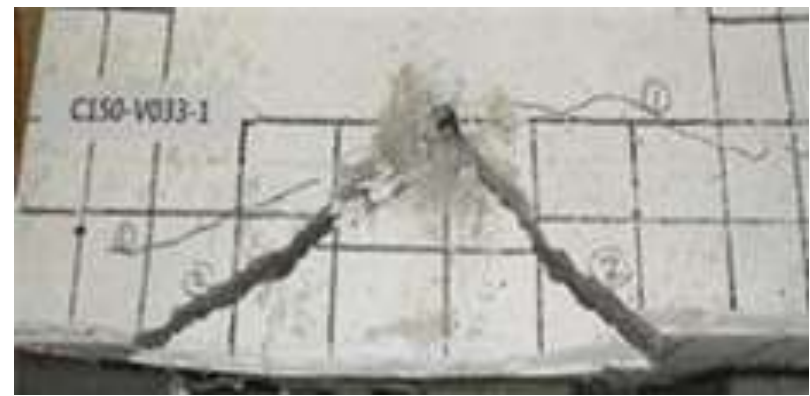

Fig. 4: Failure shape of the anchor specimen in the SFRC with the fiber volume fraction of $0.33 \%$

\subsection{Load and Displacement Curves}

Fig. 5 shows the load and displacement curves of anchors in the unreinforced and SFRC concrete obtained from the shear tests. The load and displacement curve of the anchor in the unreinforced concrete almost linearly increased up to the cracking of concrete, which occurred at approximately $85 \%$ of the maximum load. The cracking load was defined as the load, at which the initial slope of the load and displacement curve suddenly changed. The inclined cracks occurred on the top surface of the anchor block and rapidly propagated to fail the anchor when vertical cracks were generated on the side surface of the anchor block.

The load and displacement curve of the anchors in the SFRC can be divided into before and after concrete cracking. The cracking load of the SFRC anchor was very similar to that of the unreinforced concrete anchor. 
The cracking of concrete was initiated on the top surface of the concrete around the anchor. After the concrete cracking, the load and displacement curves were significantly different from the unreinforced concrete anchor. As shown in Fig. 5, the load and displacement resistance of the anchors embedded in SFRC was greatly improved as the fiber volume fraction increased. After the cracking load, the load resistance continuously increased to show the displacement hardening behavior until the maximum load. After reaching the maximum load, the load gradually decreased to fail the anchor.

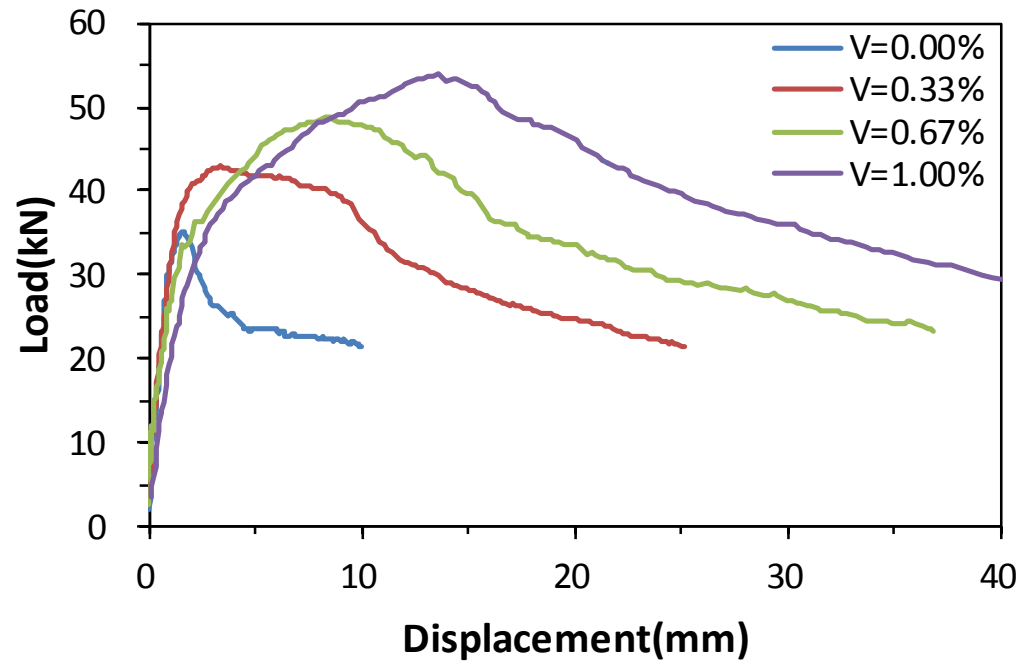

Fig. 5: Load and displacement curves of the anchors in the unreinforced and SFRC concrete.

\subsection{Cracking and Ultimate Strengths}

The cracking and maximum loads of the anchors with increasing fiber volume fraction are indicated in Fig. 6. The cracking load was indifferent with the inclusion of steel fibers until the fiber volume fraction of $1.0 \%$. The maximum load was in proportional to the fiber volume fraction. Compared to the maximum the load of the anchor in the unreinforced concrete, that of the anchor in SFRC with the fiber volume fraction of $1.0 \%$ increased by approximately $59.1 \%$.

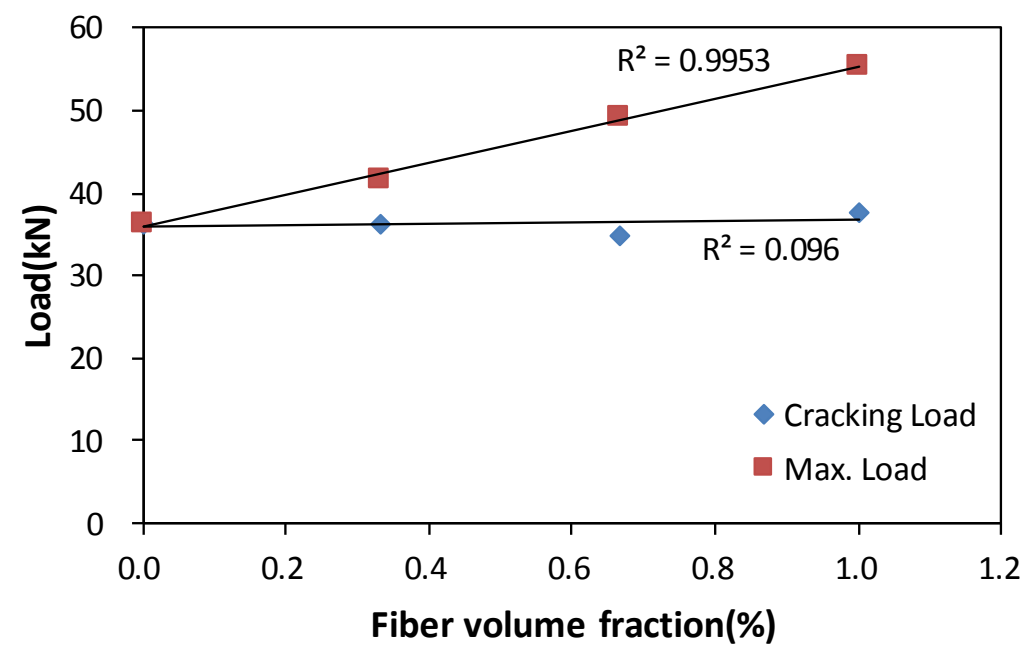

Fig. 6: Cracking and ultimate loads of the anchors with the increase in the steel fiber volume fraction

\section{Conclusions}

The shear behavior and breakout resistance of anchors in the unreinforced and SFRC concrete were evaluated in this study. The main conclusions from this study are as follows: 
- After the concrete cracking, the load and displacement resistance of the anchors in the SFRC greatly improved as the fiber volume fraction increased. The load resistance continuously increased to show the displacement hardening behavior until the maximum load.

- The cracking load of the SFRC anchors was very similar to that of the unreinforced concrete anchors, regardless of the steel fiber volume fraction. The maximum resistance of the anchors concrete breakout failure almost linearly increased with increasing steel fiber volume fraction.

\section{Acknowledgements}

This study was supported by a grant (NRF-2016R1D1A1B03935722) from Basic Science Research Programs through the National Research Foundation (NRF) of Korea.

\section{References}

[1] Y.M. Park, T.H. Kim, D.H. Kim, C.H. Kang and J.H. Lee, "Breakout shear strength of cast-in-place anchors using shaking table tests," Proceedings of the Institution of Civil Engineers-Structures and Buildings, 2017, pp.1-12. doi.org/10.1680/jstbu.16.002411

[2] ACI 318-11, Building Code Requirements for Structural Concrete and Commentary, American Concrete Institute (ACI), Farmington Hills, MI, USA, 2011.

[3] J.P. Romualdi and G.B. Batson, "The mechanics of crack arrest in concrete," ASCE Journal of Engineering Mechanics Division, vol. 89 (EM3), pp. 147-168, 1983.

[4] L. Vandewalle, "Influence of tensile strength of steel fibre on toughness of high strength concrete" in Proc. of $3^{\text {rd }}$ International Workshop on High Performance Cement Composites, 1999, pp. 331-338.

[5] G. Batson, "Steel fiber reinforced concrete," Material Science and Engineering, vol. 25, pp. 53-58, 1976.

[6] Y.K. Kwak, M.O. Eberhard, W.S. Kim, and J.B. Kim, "Shear strength of steel fiber reinforced concrete beams without stirrups," Structural Journal, vol. 99, pp. 530-538, 2002.

[7] ETAG 001, Guideline for European Technical Approval of Metal Anchors for Use in Concrete, European Organization for Technical Approvals, Brussels, 2012. 